\title{
Effect of combined water drinking test and dark room provocative testing in Caucasian eyes with narrow angles
}

Citation for published version (APA):

Römkens, H. C. S., Beckers, H. J. M., Schouten, J. S. A. G., Berendschot, T. T. J. M., \& Webers, C. A. B. (2022). Effect of combined water drinking test and dark room provocative testing in Caucasian eyes with narrow angles. Eye, 36(1), 167-174. https://doi.org/10.1038/s41433-021-01398-0

Document status and date:

Published: 01/01/2022

DOI:

10.1038/s41433-021-01398-0

Document Version:

Publisher's PDF, also known as Version of record

\section{Document license:}

Taverne

\section{Please check the document version of this publication:}

- A submitted manuscript is the version of the article upon submission and before peer-review. There can be important differences between the submitted version and the official published version of record.

People interested in the research are advised to contact the author for the final version of the publication, or visit the DOI to the publisher's website.

- The final author version and the galley proof are versions of the publication after peer review.

- The final published version features the final layout of the paper including the volume, issue and page numbers.

Link to publication

\footnotetext{
General rights rights.

- You may freely distribute the URL identifying the publication in the public portal. please follow below link for the End User Agreement:

www.umlib.nl/taverne-license

Take down policy

If you believe that this document breaches copyright please contact us at:

repository@maastrichtuniversity.nl

providing details and we will investigate your claim.
}

Copyright and moral rights for the publications made accessible in the public portal are retained by the authors and/or other copyright owners and it is a condition of accessing publications that users recognise and abide by the legal requirements associated with these

- Users may download and print one copy of any publication from the public portal for the purpose of private study or research.

- You may not further distribute the material or use it for any profit-making activity or commercial gain

If the publication is distributed under the terms of Article $25 \mathrm{fa}$ of the Dutch Copyright Act, indicated by the "Taverne" license above, 


\title{
Effect of combined water drinking test and dark room provocative testing in Caucasian eyes with narrow angles
}

\author{
Hellen C. S. Römkens ${ }^{1} \cdot$ Henny J. M. Beckers ${ }^{1}$ Jan S. A. G. Schouten $\mathbb{1}^{1,2} \cdot$ Tos T. J. M. Berendschot $\mathbb{1}^{1}$ • \\ Carroll A. B. Webers ${ }^{1}$
}

Received: 19 March 2020 / Revised: 30 December 2020 / Accepted: 8 January 2021

(c) The Author(s), under exclusive licence to The Royal College of Ophthalmologists 2021

\begin{abstract}
Purpose To assess the usefulness of water drinking test and dark room provocative testing (WDT + DRPT) in current clinical practice by evaluating input parameters from Swept-source Optical Coherence Tomography (SS-OCT) images, and to determine if clinical factors like axial length, central endothelial cell count (CECC) and retinal nerve fibre layer thickness (RNFL) thickness are associated with a positive WDT + DRPT.

Methods SS-OCT examination was performed in consecutive subjects presenting as new patients in the outpatient clinic aged $>40$ years. If at least one eye met the inclusion criteria (anterior chamber angles $<20^{\circ}$ and anterior chamber depth $<$ $2.5 \mathrm{~mm}$ on SS-OCT), subjects were included in this study and WDT + DRPT was carried out. The eye with the smallest angle was analysed. The difference in parameters between eyes with a positive $(\geq 8 \mathrm{mmHg})$ and negative $(<8 \mathrm{mmHg})$ increase in intraocular pressure (IOP) after WDT + DRPT were statistically analysed. Second, the correlation between IOP increase after WDT + DRPT and anterior chamber angle parameters (RNFL thickness, CECC and axial length) was studied. Results A total of 95 subjects with a mean age of 64 years were included. There was an association between IOP increase after WDT + DRPT and anterior chamber angle characteristics, however this was not of clinical significance. No positive results after WDT + DRPT were found in patients with anterior chamber angles $\geq 20^{\circ}$.

Conclusions The present findings indicate that this combined provocative test has no definite correlative or predictive value in angle closure disease. Further, the test is not useful in predicting early diagnosis or possible CECC or RNFL loss.
\end{abstract}

\section{Introduction}

Primary angle closure (glaucoma) $(\mathrm{PAC}(\mathrm{G}))$ is a major cause of visual impairment and blindness. Although more rare than primary open angle glaucoma (POAG), the disease often causes more devastating visual field loss, with a three to four times greater risk of blindness compared to POAG [1, 2]. PACG accounts for $50 \%$ of all blind glaucoma patients and is often underdiagnosed [3]. Many patients experience no symptoms and are therefore not diagnosed until in a late stage of the disease, after severe visual field loss has occurred. In the absence of correct angle assessment, patients with

Hellen C. S. Römkens

hellen.romkens@mumc.nl

1 Maastricht University Medical Center, Maastricht, the Netherlands

2 Canisisus Wilhelmina Ziekenhuis, Nijmegen, the Netherlands
PAC(G) may also be misdiagnosed as open angle glaucoma and (under)treated accordingly [4].

Dark room provocative testing (DRPT) has been a popular, however also controversial, method in the past decades to assess the risk of developing glaucoma in subjects with narrow angles or angle closure, primary angle closure suspects (PACS). Crowding of the iris in the anterior chamber angle after pupil dilation together with an increased pressure gradient between the posterior and anterior chamber (pupillary block) is believed to provoke a rise in intraocular pressure (IOP) [5]. Conventional DRPT accordingly aims to provoke this pupillary block response with elevated IOP. The clinical value of DRPT has however been subject to considerable discussion because of its high false-positive and false-negative rates [6]. It can be interpreted as a load test to detect the angle's tendency to remain open under dynamic conditions.

New imaging techniques like optical coherence tomography (OCT) are capable of visualizing and quantifying presumed structural changes in the detection of $\mathrm{PAC}(\mathrm{G})$. 
Swept-source optical coherence tomography (SS-OCT) offers high resolution visualization of the anterior chamber depth and angle anatomy. SS-OCT uses infrared light with a wavelength of $1310 \mathrm{~nm}$ as the light source and has therefore little effect on the pupil size. It is capable of imaging the anterior chamber angle in a darkened room [7, 8]. SS-OCT thus provides a quick non-contact assessment and when available can be used as a first screening test to determine which patients need additional diagnostics with e.g. gonioscopy and possibly further glaucoma diagnostics and treatment.

Also, retinal nerve fibre layer (RNFL) thickness can be measured, with posterior segment OCT. RNFL loss after acute angle closure glaucoma (AAC) is well described [9], however, the relation between a positive DRPT and RNFL loss is not well established. Besides well-known structural changes of RNFL thickness, it has been reported that in Asians the corneal endothelial cell count (CECC) is significantly lower in chronic PACG, compared to controls $[10,11]$. It has also been shown that short axial length is a risk factor for PACG in Asians [12, 13]. However, data on provocative testing and correlation with biometric and structural changes is lacking.

Provocative testing is often described as a time-consuming, cumbersome and uncomfortable test for both the patient as the practitioner. The question arises if there is still a place for WDT + DRPT in the face of emerging newer techniques like OCT that have the potential of distinguishing more easily and more accurately the need for further evaluation with gonioscopy and subsequently the patient's risk of developing AAC and glaucomatous damage.

In the present study we wanted to assess the usefulness of provocative testing in current clinical practice by evaluating input parameters from SS-OCT images. Our second goal was to determine if clinical parameters such as axial length, CECC and RNFL thickness are associated with a positive WDT + DRPT.

\section{Methods}

This study was conducted in accordance with the tenets of the Declaration of Helsinki and was approved by the Maastricht University Medical Center + (Maastricht, The Netherlands) institutional review board. Examinations of individuals participating in this study were carried out from April 2014 to April 2015.

\section{Subjects}

The present study is part of the Detection of Angle Closure study (DTAC-study), a hospital-based study in the
Netherlands, carried out in the outpatient clinic of the University Eye Clinic of the Maastricht University Medical Center+ $(\mathrm{MUMC}+)$ to detect the presence of angle closure in Caucasian patients with the use of SS-OCT.

Eligible subjects were consecutive new patients, presenting at the outpatient clinic, meeting the following inclusion criteria: no history of eye disease(s), Caucasian race, age $40-80$ years, and willing and able to comply with scheduled visits and other study procedures. The purpose of the screening of consecutive new patients was to generate reference values for anterior chamber morphometrics to facilitate the interpretation of anterior chamber images acquired with SS-OCT in a Caucasian population [14]. From these consecutive new patients, patients with narrow angles and meeting the following criteria were included in this study, and WDT + DRPT was performed.

Participants were eligible for inclusion if they met one or more of the following criteria in at least one eye:

- Iridotrabecular contact (ITC) in $\geq 2$ quadrants on SSOCT in darkened conditions

- Trabecular Iris angle (TIA) $<20^{\circ}$ (in 0 and $180^{\circ}$ ) AND anterior chamber depth (ACD) $<2.5 \mathrm{~mm}$ on SS-OCT in darkened conditions.

If one eye met the inclusion criteria, both eyes of the patient were included in the study. To analyse the effect in the eye with the anterior segment most at risk of IOP increase after WDT + DRPT, the eye with the narrower angle was used for the analysis.

Caucasian ancestry (for both parents) was determined by self-reporting. The term "Caucasian" for purposes of this study comprised only European-derived white people. If there was any doubt about the patient's eligibility in regard to ancestry or if the questions could not be answered, patients were not included. After explaining the nature of the study (including all described measurements), all subjects gave their signed informed consent. A subject was excluded if there was a history of eye disease (i.e. (secondary) glaucoma or any other significant eye disease), or any condition (i.e., (previous)) intraocular laser/incisional surgery or ophthalmological procedure or treatment, an eye condition/abnormality that could affect the acquisition/ reliability of measurements, (e.g. vitreous haemorrhage, uveitis, intraocular trauma, significant corneal opacity), or if the participant was unable to adequately communicate and/ or understand instructions.

\section{Diagnostic tests}

Included participants underwent a routine ophthalmic examination, including visual acuity and refractive error 
measurements, slit lamp examination, Goldmann applanation tonometry and funduscopy of both eyes.

Anterior chamber data recording was carried out with SS-OCT (Casia SS-1000 OCT; Tomey, Nagoya, Japan). One image was taken of both eyes, with undilated pupils, in a darkened room, with subjects looking at the internal fixation light. SS-OCT was performed under standard dark room ( $<10$ Lux illumination) conditions for all image acquisitions. Images were acquired in the angle analysis mode. This scan mode consists of 128 radial B-scans, 16 $\mathrm{mm}$ long, automatically aligned on the corneal centre. Each B-scan includes $512 \mathrm{~A}$-scans. The measurement time in this scan mode is $2.4 \mathrm{~s}$. The anterior chamber and angle parameters were analysed using the available software for SS-OCT (Version 6; Tomey, Nagoya, Japan). Image analysis was performed by a single investigator (HR) through manual placement of the iridocorneal angle tool at the scleral spur (reference point for the relative position of the trabecular meshwork) in the temporal and nasal angle $\left(0^{\circ}\right.$ to $180^{\circ}$ meridian $)$, after which the intrinsic software of the SS-OCT automatically calculated the trabecular iris angle (TIA) at $500 \mu \mathrm{m}$ and $750 \mu \mathrm{m}$, anterior chamber depth (ACD) and lens vault (LV). The nasal and temporal angle values were used for anterior chamber angle analysis [15].

Additionally, participating subjects underwent WDT + DRPT. Subjects were in a sitting position. IOP was measured with Goldmann applanation tonometry (Haag-Streit, Bern, Switzerland). The examiner measuring the IOP was blinded during the measurement for previous results and the tonometer knob (display for the value of the IOP), was covered with a cap over the tonometry reading. IOP was measured as a single reading prior to the start of the WDT + DRPT and immediately after provocation. After baseline IOP measurement, each subject was asked to drink $1 \mathrm{~L}$ of water in 15 minutes (water drinking), after which a prone position in a darkened room was adopted. The lights were turned off and the subjects were instructed to keep their eyes open. The subjects put on dark goggles and sat in the dark room with the lights off for 45 minutes (dark room provocation). During that period, the subjects were instructed to stay awake. After 45 minutes, the IOP was measured directly following the same procedure as at the start of WDT + DRPT. During the test no other food or drinks were allowed. All imaging measurements (SS-OCT, RNFL thickness, axial length and CECC) were done prior to the WDT + DRPT.

Based on the original design by Higgit in 1954, reports have also shown that provocative testing can induce an IOP rise in open angle glaucoma patients, which might explain the low specificity [16]. To decrease the number of false positives, a cut off value for a positive test result of $\geq 8 \mathrm{mmHg}$ was chosen, since this level of IOP rise occurred in only $1 \%$ of subjects with open angle glaucoma [16]. All imaging measurements (SS-OCT, RNFL thickness, axial length en CECC) were done prior to the DRPT.

In total, 100 patients were included in the study who received examinations to identify any structural and functional changes, indicating glaucomatous damage, followed by WDT + DRPT, except for those with advanced glaucomatous damage (MD worse than $-12 \mathrm{~dB}$ or $\mathrm{CD}$ ratio $\geq 0.8$ ). These latter patients were already diagnosed with PACG and an IOP rise during WDT + DRPT would give no extra information on the state of the disease. Therefore, a WDT + DRPT was not justifiable in this patient group $(n=5)$.

The clinical stage of primary angle closure disease of the patients undergoing WDT + DRPT was assessed with gonioscopy and the presence of glaucomatous damage. This led to the following classification: primary angle closure suspect (PACS) $(n=53 ; 55.8 \%)$, primary angle closure $(\mathrm{PAC})(n=39 ; 41.1 \%)$, and PACG $(n=3 ; 3.2 \%)$.

RNFL thickness was measured with the Spectralis OCT (Heidelberg Engineering, Heidelberg, Germany), quantification of axial length was measured with the IOLMaster (Carl Zeiss Meditec, Dublin, CA) and CECC was measured with the Topcon (Topcon Eye Care company, Capelle aan den Ijssel, The Netherlands). The patient's pupils were not dilated before these tests. Analysis was performed by a single investigator (HR), with extensive experience in acquiring reliable images and measurements.

\section{Analysis}

All data were analysed using a statistical software package (SPSS 25; SPSS Inc., Chicago, IL, USA). All available data were extracted from the analyses taken by SS-OCT. First, histograms and frequency analyses were performed to obtain information on distribution of the data. To analyse the effect in the eye with the anterior segment most at risk of IOP increase after WDT + DRPT, the eye with the narrower angle was used for the analysis. As a result, it was possible that some patients who were included in the study based on their left eye, had a TIA $>20^{\circ}$ in their right eye. Also, the association between WDT + DRPT, biometric parameters, structural parameters and IOP after WDT + DRPT was assessed. The Pearson correlation test was used to detect a correlation.

The cut-off value of a positive WDT + DRPT was set at an IOP increase of at least $8 \mathrm{~mm} \mathrm{Hg}$ [16]. $T$-tests were used to compare differences in characteristics between the two groups. A $p$ value of $<0.05$ was considered statistically significant. 
Table 1 Demographic data of the study group and ocular characteristics of positive and negative eye.

\begin{tabular}{|c|c|c|c|c|c|}
\hline \multicolumn{6}{|l|}{ Patient demographics and ocular characteristics } \\
\hline & $N$ (subjects, $(\%))$ & Mean & SD & Range & $P$ value \\
\hline Gender (female/male) & $61 / 34(64 / 36 \%)$ & & & & \\
\hline Negative & $51 / 27(65 / 35 \%)$ & & & & 0.61 \\
\hline Positive & $10 / 7(59 / 41 \%)$ & & & & \\
\hline Age (years) & 95 & 63.7 & 10.4 & $42-79$ & \\
\hline Negative & 78 & 63.1 & 10.4 & $42-79$ & 0.21 \\
\hline Positive & 17 & 66.6 & 9.9 & $45-79$ & \\
\hline Refractive error (Diopters) & 95 & 1.5 & 2.3 & $-9.0-8.75$ & \\
\hline Negative & 78 & 1.6 & 2.3 & $-9.0-8.75$ & 0.68 \\
\hline Positive & 17 & 1.3 & 1.9 & $-4.3-4.4$ & \\
\hline Pre-test IOP $(\mathrm{mmHg})$ & 95 & 13.3 & 2.9 & $9-22$ & \\
\hline Negative & 78 & 13.2 & 2.7 & $9-21$ & 0.95 \\
\hline Positive & 17 & 13.3 & 3.8 & $10-22$ & \\
\hline Post-test IOP (mmHg) & 95 & 18.0 & 4.9 & $9-37$ & \\
\hline Negative & 78 & 16.7 & 3.7 & $9-26$ & $<0.01$ \\
\hline Positive & 17 & 23.7 & 6.0 & $19-37$ & \\
\hline Anterior chamber angle temporal $\left({ }^{\circ}\right)$ & 95 & 10.2 & 6.0 & $0-19.4$ & \\
\hline Negative & 78 & 10.5 & 6.0 & $0-19.4$ & 0.40 \\
\hline Positive & 17 & 9.1 & 6.0 & $0-16.8$ & \\
\hline Anterior chamber angle nasal $\left({ }^{\circ}\right)$ & 95 & 11.4 & 5.4 & $0-19.9$ & \\
\hline Negative & 78 & 11.9 & 4.9 & $0-19.6$ & 0.14 \\
\hline Positive & 17 & 9.2 & 7.0 & $0-19.9$ & \\
\hline Anterior chamber depth (mm) & 95 & 2.2 & 0.2 & $1.6-2.7$ & \\
\hline Negative & 78 & 2.2 & 0.2 & $1.6-2.6$ & 0.91 \\
\hline Positive & 17 & 2.2 & 0.3 & $1.7-2.7$ & \\
\hline Lens Vault (mm) & 95 & 0.8 & 0.2 & $0.3-1.5$ & \\
\hline Negative & 78 & 0.8 & 0.2 & $0.3-1.5$ & 0.68 \\
\hline Positive & 17 & 0.8 & 0.3 & $0.4-1.3$ & \\
\hline Axial length (mm) & 95 & 22.8 & 1.0 & $20.6-25.4$ & \\
\hline Negative & 77 & 22.8 & 1.0 & $20.6-25.4$ & 0.98 \\
\hline Positive & 17 & 22.8 & 0.9 & $21.4-24.8$ & \\
\hline Central endothelial cell count (number of cells) & 93 & 2371 & 351 & $1420-3019$ & \\
\hline Negative & 76 & 2392 & 352 & $1420-3019$ & 0.21 \\
\hline Positive & 17 & 2275 & 338 & $11,697-2770$ & \\
\hline Retinal nerve fibre layer temporal superior $(\mu \mathrm{m})$ & 94 & 130 & 20 & $94-217$ & \\
\hline Negative & 77 & 130 & 20 & $94-217$ & 0.68 \\
\hline Positive & 17 & 128 & 21 & $94-164$ & \\
\hline
\end{tabular}

$S D$ standard deviation

\section{Results}

\section{Study population}

A total of 95 subjects were included in the study, $34(36 \%)$ male, mean age $64 \pm 10$ years (range 42-79). There were 17 subjects with a IOP increase of $\geq 8 \mathrm{~mm} \mathrm{Hg}$ in the smallest eye after WDT + DRPT. There were no adverse events during or after WDT + DRPT, and the IOP rise could be controlled with medication in all cases, with no patients developing AAC. Demographic characteristics are summarized in Table 1.

\section{Positive WDT + DRPT}

There were neither significant differences in age and sex between positive $(\geq 8 \mathrm{mmHg})$ and negative results after WDT + DRPT, nor in other biometric and structural characteristics (see Table 1). 


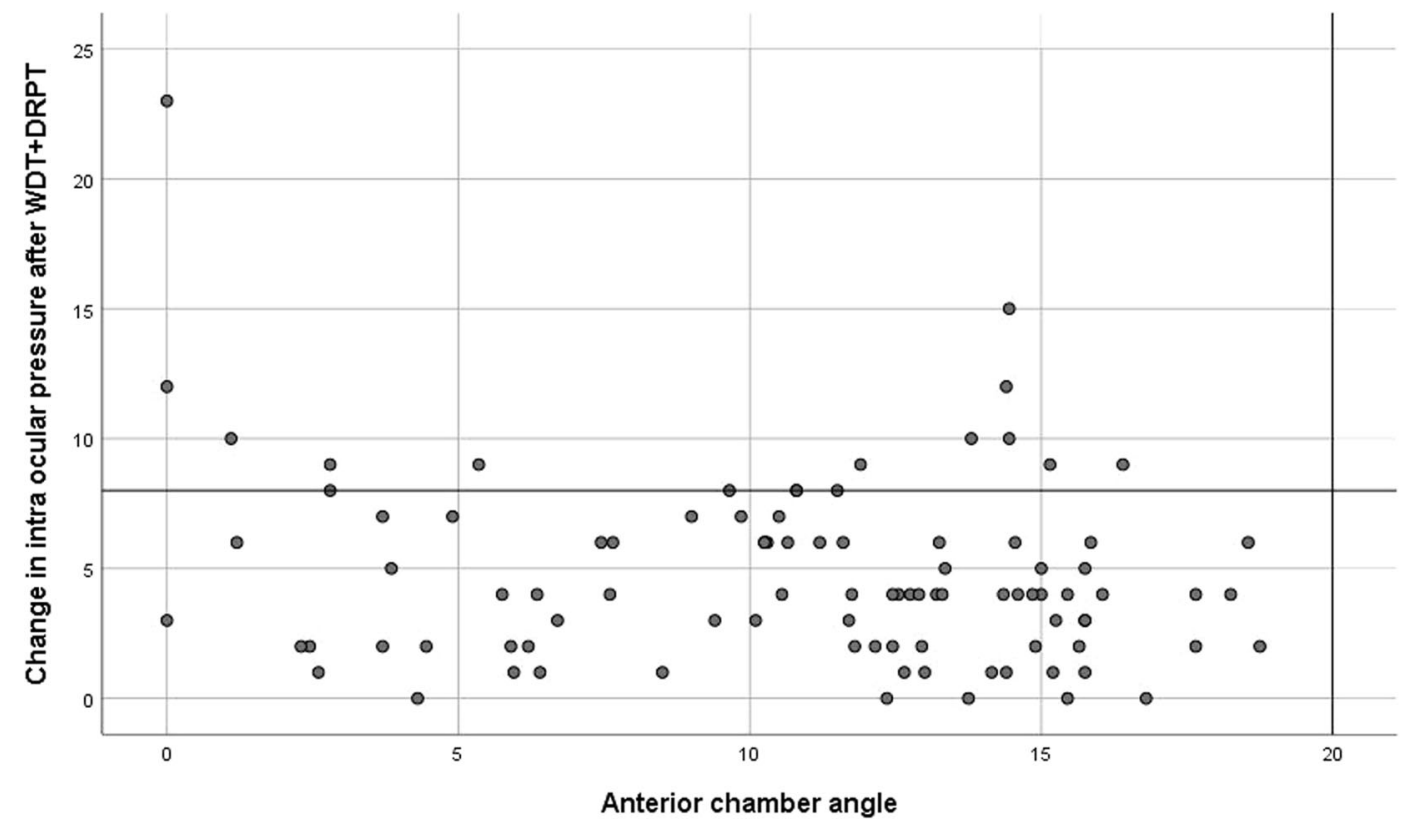

Fig. 1 Scatter plot of IOP increase after WDT + DRPT compared with mean anterior chamber angle of the narrower eye. The vertical red line is set at $20^{\circ}$ anterior chamber angle, considering $<20^{\circ}$ as

\section{Anterior chamber angle and WDT + DRPT}

Figure 1 shows the change in IOP after WDT + DRPT as a function of the mean of the temporal and nasal anterior chamber angle. There was a correlation between the degree of angle closure and the amount of IOP increase after WDT + DRPT in the smallest eye $(r=-0.21, p=0.044)$, however, this effect was caused by one subject. If this subject was excluded from the analysis the effect was no longer significant $(r=-0.10, p=0.32)$. Lens status of patients classified as no cataract $(n=64 ; 67.4 \%)$, lens sclerosis $(n=19 ; 20.0 \%)$, and early nuclear cataract $(n=12 ; 12.7 \%)$, did not predict the outcome of WDT + DRPT. There was also no correlation between the amount of IOP increase after WDT + DRPT and lens vault $(r=0.022 ; p=0.83)$ or anterior chamber depth $(r=-0.15 ; p=0.15)$. There were no patients with a mature cataract inducing IOP rise and/or AAC at presentation.

\section{Structural changes and WDT + DRPT}

For the smallest eye, we found a correlation between RNFL thickness (temporal superior) and IOP increase after WDT + DRPT $(r=-0.25, p=0.015)$. Here again, this effect was caused by the same subject that induced the correlation for the degree of angle closure. If this subject was excluded from the analysis the effect was no longer significant $(r=-0.20, p=0.053)$.

There was no correlation between axial length and CECC as a function of IOP increase after DRPT $(r=-0.08, p=$ $0.44 ; r=0.20, p=0.058$ ). angle closure and $\geq 20^{\circ}$ as open. The horizontal red line indicates the cut-off value of $8 \mathrm{mmHg}$. An IOP increase of $\geq 8 \mathrm{mmHg}$ demonstrates a positive WDT + DRPT.

\section{Discussion}

Our present purpose was to evaluate the clinical usefulness of WDT + DRPT after determining narrow angles by SSOCT as a risk factor for elevated IOP in angle closure patients. Our results are consistent with previous studies in which a low sensitivity, low specificity and low diagnostic value of (WDT) + DRPT was shown [17, 18].

Since provocative testing aims to provoke a pupillary block with elevated IOP, it has been used to determine patients at risk of AAC. Pupillary block is an important and treatable underlying mechanism of $\mathrm{PAC}(\mathrm{G})$. Laser peripheral iridotomy (LPI) has been the first-line treatment for AAC, PACS and PAC $(\mathrm{G})$ since the $70 \mathrm{~s}$ as it is believed to eliminate pupillary block $[19,20]$.

Although LPI is widely performed, there is a lack of consensus on when to perform a prophylactic LPI in PACS to reduce the risk of development of AAC. It has been shown that the anterior chamber angle first increases markedly after treatment with LPI, whereas thereafter a significant decrease is observed at 18 months after treatment [21]. Untreated eyes show a more rapid decrease in anterior chamber angle over the same time period. However, in the most recent study by He et al., the incidence of developing glaucoma from PACS was low and LPI had little beneficial effect in prevention of AAC after 6 years [22]. Therefore, prophylactic LPI was not recommended in this study. It has also been reported in the EAGLE trial that clear lens extraction is superior over LPI in patients with PAC with high IOP and PACG in establishing better quality of life and better IOP control, preventing 
blindness [23]. It has been shown in earlier studies that LPI reduces pupillary block and consequently a lower IOP rise after mydriasis was seen. Contradictory to this, a higher IOP elevation in WDT after LPI has also been found [24, 25]. This is thought to be the effect of pigment release and inflammation after performing LPI. Thus, there seems to be no conclusive evidence yet [26].

From these recent studies one could question the need of LPI for everyone with narrow angles and perhaps give more consideration to identify those patients at high risk of developing $\operatorname{PAC}(G)$ in order to initiate a personalized treatment regimen. The present findings indicate that the WDT + DRPT may be of some use as an extra screening tool when in doubt of performing LPI in patients with angles $<20^{\circ}$. A positive WDT + DRPT may convince the patient to undergo treatment, however the patient must be warned that the result of this test may still be inconclusive. Second, this study demonstrates that the degree of angle closure or other angle characteristics on SS-OCT cannot predict a positive WDT + DRPT, leading to the conclusion that (WDT) + DRPT cannot be used to further refine the diagnosis of $\mathrm{PAC}(\mathrm{G})$ and to identify patients who are at risk for an attack of AAC.

IOP rise following water drinking in open angle glaucoma is thought to be the consequence of reduced outflow facility [27]. However, the exact mechanism of IOP rise after WDT is yet to be determined. It was found that there was no variation in hematocrit, total plasma osmolality of plasma colloid osmotic pressure, which could not explain the IOP increase by vitreous hydration of increased aqueous ultrafiltration [28].However, it can be concluded that after WDT an increase in IOP is seen in patient with reduced outflow facility.

It is hypothesized that an increase in choroidal thickness could possibly lead to an increase in pupillary block mechanism and could contribute to the development of angle closure in smaller eyes compared to eyes with a wider anterior segment anatomy. In smaller eyes, expansion of the choroid would lead to a greater effect in IOP rise and thus a greater pupillary block $[29,30]$. Arora et al. described the unique effect of choroidal thickness change in angle closure patients after water drinking test [31]. They concluded that an increase in choroidal thickness and a decrease in ACD after water drinking test was observed in patient with angle closure, but this effect was not seen in open angle patients. IOP increase after the water drinking was not fully explained by increase in choroidal thickness. However, it was described that choroidal thickness was greater at baseline in eyes with angle closure, which confirms the known relation between smaller eyes and a thicker choroid.

In Asians, other biometric parameters like shorter axial length were reported to be associated with a positive WDT + DRPT [32]. We only measured Caucasian subjects, which might explain the different finding in our study in which axial length shows no association with a positive WDT + DRPT.

Chen et al. concluded that CECC was decreased in patients after AAC compared with normal eyes [33]. However, in the present study there was no correlation between IOP increase after WDT + DRPT and CECC. It may be hypothesized that there is no CECC loss detectable in eyes with PACS or early PAC(G).

Glaucomatous optic neuropathy is characterized by a progressive loss of retinal ganglion cells and their axons and as a result thinning of RNFL. Therefore, RNFL thickness is used for early diagnosis and rating of glaucoma, which nowadays is easily implemented in daily clinical practice with OCT measurements. Thinning of the RNFL thickness indicates progression from primary angle closure to primary angle closure glaucoma and thus treatment should be implemented. Taking into consideration that structural changes are easily measured and detectable over time, it might be questioned if WDT + DRPT (with all its limitations mentioned earlier) is still necessary when RNFL thinning on OCT measurement already confirms the diagnosis of glaucomatous damage and early changes.

Potential limitations of this study should also be mentioned. This was a cross-sectional study that did not look at changes over time. As for any hospital-based study, there is a risk of bias on the inclusion of the study population. However, participating subjects were consecutively included and the in- and exclusion criteria were thoroughly defined at baseline. Patients $(n=5)$ who participated and, after receiving fundus examination and visual field tests, turned out to have advanced glaucomatous damage (MD worse than $-12 \mathrm{~dB}$ or $\mathrm{CD}$ ratio $\geq 0.8$ ) at the initial visit, did not receive WDT + DRPT and were not included in this analysis. It was assumed that these patients would already be correctly diagnosed with structural and functional measurements and WDT + DRPT would not provide additional information, since it was evident that treatment should be initiated. Additionally, although a larger group was included than in previous studies in literature on this subject, the number of included subjects was still relatively small. It must further be noted that SS-OCT is not a standard tool yet, available in any ophthalmic practice. Strengths of the current study include low dropout, objective quantitative assessment of various parameters and testing in a clearly described ethnic group.

In conclusion, WDT + DRPT dilates the pupil in the dark and may induce susceptible angles to further narrow or even fully close, however no definite correlative or predictive value in the degree of angle closure disease and risk of development of AAC has been found. Maximum provocation through WDT + DRPT does not accurately clarify which patients are at risk of AAC and/or angle 
closure disease. Also, we found no relation between the degree of angle closure and the rise in IOP after WDT + DRPT. Therefore, WDT + DRPT is not advised as a standard clinical test in daily clinical practice.

Further, the test is not useful in predicting early diagnosis or possible CECC or RNFL loss. New imaging devices like SS-OCT are capable of detecting angle closure and indicate which patients need further assessment with gonioscopy and visual field testing. These tests will in most cases suffice to select patients who need further diagnostics and possibly treatment in preventing progression of their primary angle closure disease.

\section{Summary}

\section{What was known before}

- Conventional DRPT aims to provoke this pupillary block response with elevated IOP.

- The clinical value of WDT + DRPT has however been subject to considerable discussion because of its high false-positive and false-negative rates.

- It can be interpreted as a load test to detect the angles tendency to remain open under dynamic conditions.

- Based on the original design by Higgit in 1954, reports have also shown that provocative testing can induce an IOP rise in open angle glaucoma patients, which might explain the low specificity.

\section{What this study adds}

- WDT + DRPT may be useful when in doubt of treatment and may be considered as an additional test for patients with angles $<20$ degrees; It is not useful in predicting early diagnosis or possible CECC or RNFL loss.

- With new anterior chamber imaging devices and quantification of the RNFL through OCT, WDT + DRPT yields only important additional clinical information in selected cases. Combining SS-OCT measurements with gonioscopy findings provides accurate information on the morphometry and extent of angle closure. In combination with accurately performed visual field testing, these new methods will in most cases suffice to define patients who need further diagnostics and possibly treatment in preventing progression of their primary angle closure disease.

Funding The author received support by the following foundations: Glaucoomfonds, Oogfonds, Landelijke Stichting voor Blinden en Slechtzienden, that contributed through UitZicht. The funding organizations had no role in the design or conduct of this research. They provided unrestricted grants.

\section{Compliance with ethical standards}

Conflict of interest The authors declare that they have no conflict of interest.

Publisher's note Springer Nature remains neutral with regard to jurisdictional claims in published maps and institutional affiliations.

\section{References}

1. Congdon NG, Friedman DS. Angle-closure glaucoma: impact, etiology, diagnosis, and treatment. Curr Opin Ophthalmol. 2003;14:70-3.

2. Wang $\mathrm{N}, \mathrm{Wu} \mathrm{H}$, Fan $\mathrm{Z}$. Primary angle closure glaucoma in Chinese and Western populations. Chin Med J. 2002;115: 1706-15.

3. Quigley HA, Broman AT. The number of people with glaucoma worldwide in 2010 and 2020. Br J Ophthalmol. 2006;90:262-7.

4. Bonomi L, Marchini G, Marraffa M, Bernardi P, De Franco I, Perfetti S, et al. Epidemiology of angle-closure glaucoma: prevalence, clinical types, and association with peripheral anterior chamber depth in the Egna-Neumarket Glaucoma Study. Ophthalmology. 2000;107:998-1003.

5. Mapstone R. Provocative tests in closed-angle glaucoma. Br J Ophthalmol. 1976;60:115-9.

6. Wilensky JT, Kaufman PL, Frohlichstein D, Gieser DK, Kass MA, Ritch R, et al. Follow-up of angle-closure glaucoma suspects. Am J Ophthalmol. 1993;115:338-46.

7. Radhakrishnan S, Goldsmith J, Huang D, Westphal V, Dueker DK, Rollins AM, et al. Comparison of optical coherence tomography and ultrasound biomicroscopy for detection of narrow anterior chamber angles. Arch Ophthalmol. 2005;123:1053-9.

8. Nolan WP, See JL, Chew PT, Friedman DS, Smith SD, Radhakrishnan S, et al. Detection of primary angle closure using anterior segment optical coherence tomography in Asian eyes. Ophthalmology. 2007;114:33-9.

9. Aung T, Husain R, Gazzard G, Chan YH, Devereux JG, Hoh ST, et al. Changes in retinal nerve fiber layer thickness after acute primary angle closure. Ophthalmology. 2004;111:1475-9.

10. Gagnon MM, Boisjoly HM, Brunette I, Charest M, Amyot M. Corneal endothelial cell density in glaucoma. Cornea. 1997;16:314-8.

11. Sihota R, Lakshmaiah NC, Titiyal JS, Dada T, Agarwal HC. Corneal endothelial status in the subtypes of primary angle closure glaucoma. Clin Exp Ophthalmol. 2003;31:492-5.

12. Aung T, Nolan WP, Machin D, Seah SK, Baasanhu J, Khaw PT, et al. Anterior chamber depth and the risk of primary angle closure in 2 East Asian populations. Arch Ophthalmol. 2005; 123:527-32.

13. Nongpiur ME, He M, Amerasinghe N, Friedman DS, Tay WT, Baskaran M, et al. Lens vault, thickness, and position in Chinese subjects with angle closure. Ophthalmology. 2011;118:474-9.

14. Romkens HC, Beckers HJ, Schouten JS, Berendschot TT, Webers CA. Reference values for anterior chamber morphometrics with swept-source optical coherence tomography in a Caucasian population. Clin Ophthalmol. 2018;12:411-7.

15. Romkens HC, Beckers HJ, Frusch M, Berendschot TT, de Brabander J, Webers CA. Reproducibility of anterior chamber angle analyses with the swept-source optical coherence tomography in young, healthy Caucasians. Investigative Ophthalmol Vis Sci. 2014;55:3999-4004.

16. Higgitt AC. The dark-room test. Br J Ophthalmol. 1954;38:242-7. 
17. Rasmussen KE, Jorgensen HA. Diagnostic value of the waterdrinking test in early detection of simple glaucoma. Acta Ophthalmol. 1976;54:160-6.

18. Friedman DS, Chang DS, Jiang Y, Huang S, Kong X, Munoz B, et al. Darkroom prone provocative testing in primary angle closure suspects and those with open angles. Br J Ophthalmol. 2019;103:1834-9.

19. Weinreb RN. Angle closure and angle closure glaucoma. The Hague, The Netherlands: Kugler Publications; 2006.

20. Robin AL, Pollack IP. Argon laser peripheral iridotomies in the treatment of primary angle closure glaucoma. Long-term followup. Arch Ophthalmol. 1982;100:919-23.

21. Jiang Y, Chang DS, Zhu H, Khawaja AP, Aung T, Huang S, et al. Longitudinal changes of angle configuration in primary angleclosure suspects: the Zhongshan Angle-Closure Prevention Trial. Ophthalmology. 2014;121:1699-705.

22. He M, Jiang Y, Huang S, Chang DS, Munoz B, Aung T, et al. Laser peripheral iridotomy for the prevention of angle closure: a singlecentre, randomised controlled trial. Lancet. 2019;393:1609-18.

23. Azuara-Blanco A, Burr J, Ramsay C, Cooper D, Foster PJ, Friedman DS, et al. Effectiveness of early lens extraction for the treatment of primary angle-closure glaucoma (EAGLE): a randomised controlled trial. Lancet 2016;388:1389-97.

24. Waisbourd M, Savant SV, Sun Y, Martinez P, Myers JS. Waterdrinking test in primary angle-closure suspect before and after laser peripheral iridotomy. Clin Exp Ophthalmol 2016; 44:89-94.
25. Razeghinejad R, Nowroozzadeh MH. Water-drinking test and pharmacologic mydriasis as provocative tests in primary angle closure suspects. J Ophthalmic Vis Res. 2019;14:267-74.

26. Karmon G, Vender T, Savir H. Evaluation of laser iridectomy in angle-closure glaucoma: provocative tests. $\mathrm{Br} \mathrm{J}$ Ophthalmol. 1982;66:471-3.

27. Vasconcelos-Moraes CG, Susanna R Jr. Correlation between the water drinking test and modified diurnal tension curve in untreated glaucomatous eyes. Clin (Sao Paulo). 2008;63:433-6.

28. Brucculeri M, Hammel T, Harris A, Malinovsky V, Martin B. Regulation of intraocular pressure after water drinking. J Glaucoma. 1999;8:111-6.

29. Quigley HA, Friedman DS, Congdon NG. Possible mechanisms of primary angle-closure and malignant glaucoma. J Glaucoma. 2003; $12: 167-80$.

30. Quigley HA. What's the choroid got to do with angle closure? Arch Ophthalmol. 2009;127:693-4.

31. Arora KS, Jefferys JL, Maul EA, Quigley HA. Choroidal thickness change after water drinking is greater in angle closure than in open angle eyes. Investigative Ophthalmol Vis Sci. 2012;53:6393-402.

32. Zahari M, Ong YM, Taharin R, Ramli N. Darkroom prone provocative test in primary angle closure glaucoma relatives. Optom Vis Sci: Off Publ Am Acad Optom. 2014;91:459-63.

33. Chen MJ, Liu CJ, Cheng CY, Lee SM. Corneal status in primary angle-closure glaucoma with a history of acute attack. J Glaucoma. 2012;21:12-6. 